\title{
IMPLEMENTASI LESSON STUDY UNTUK MENINGKATKAN MINAT BELAJAR MAHASISWA MELALUI METODE PEMBELAJARAN SEMINAR GROUP
}

\author{
Lukmanul Akhsani \\ Universitas Muhammadiyah Purwokerto \\ luk_akh@yahoo.com
}

Kusno

Universitas Muhammadiyah Purwokerto

\author{
Ahmad \\ Universitas Muhammadiyah Purwokerto
}

\begin{abstract}
Lesson Study (LS) is the learning of assessment activities carried out by a group of teachers / faculty collaborative and sustainable to test and improve the effectiveness of learning. In this study, the implementation of lesson study to improve student interest in learning through the learning method Seminars Group. The results obtained by analysis of the average increase student interest in learning. Cycle 1 gained an average interest of students 67, 86 in the category of high interest in learning. In the first cycle of the findings of the observer focused on seating position make it difficult for the observer to move and students still do not concentrate on learning. Seat that is positioned in groups. Cycle 2 gained an average of 70.78 in the category of student interest high interest in learning. In Cycle 2 focused on the position of the seat. Apparently after the seat is positioned to the observer, the motion less students, so many students are easily sleepy and easier to jaw, with no attention to the lecturer. Cycle 3 gained an average of 72.59 students' interest in the category of high interest. In the do cycle 3, the observer gain some findings that many students were late, and there are still some students who own story. This is possible because they are too short presentation and question focus. Suggestions observer, lecturer models the moderator in the learning process. Cycle 4 gained an average of 72.71 in the category of student interest high interest in learning. Learning is in conformity with the plan, but there are still students who do the work of other subjects. This is a model professor responded by asking questions that make students think, re-concentration of students with learning again.
\end{abstract}

Keywords: Lesson Study, interests, seminar group.

ABSTRAK. Lesson Study (LS) merupakan kegiatan pengkajian pembelajaran yang dilakukan oleh sekelompok guru/dosen secara kolaboratif dan berkelanjutan untuk menguji dan meningkatkan keefektifan pembelajaran. Dalam penelitian ini implementasi lesson study untuk meningkatkan minat belajar mahasiswa melalui metode pembelajaran Seminar Group. Hasil analisis diperoleh rata-rata minat belajar mahasiswa meningkat. Siklus 1 diperoleh rata-rata minat mahasiswa 67,8 6 masuk kategori minat belajar tinggi. Dalam siklus 1 temuan dari observer terfokus pada posisi tempat duduk masih mempersulit observer untuk bergerak dan mahasiwa masih belum konsentrasi pada 
pembelajaran. Tempat duduk agar diposisikan berkelompok. Siklus 2 diperoleh rata-rata minat mahasiswa 70,78 masuk kategori minat belajar tinggi. Dalam Siklus 2 terfokus pada posisi tempat duduk. Ternyata setelah tempat duduk diposisikan untuk observer, mahasiswa ruang geraknya kurang sehingga banyak mahasiswa yang mudah mengantuk dan lebih mudah untuk berbicara sendiri dengan dengan tidak memperhatikan dosen. Siklus 3 diperoleh rata-rata minat mahasiswa 72,59 masuk kategori minat tinggi. Pada tahap do di siklus 3, observer mendapatkan beberapa temuan yaitu mahasiswa banyak yang terlambat, dan masih ada beberapa mahasiswa yang cerita sendiri. Hal ini dimungkinkan kerena presentasi yang terlalu singkat dan pertanyaan tidak fokus. Saran observer, dosen model menjadi moderator dalam proses pembelajaran. Siklus 4 diperoleh rata-rata minat mahasiswa 72,71 masuk kategori minat belajar tinggi. Pembelajaran sudah sesuai dengan rencana, namun masih ada mahasiswa yang mengerjakan tugas matakuliah lain. Hal ini ditanggapi dosen model dengan memberi pertanyaan yang membuat mahasiswa berpikir, mahasiswa kembali konsentrasi lagi dengan pembelajaran.

Kata Kunci: Lesson Study, minat, seminar group.

\section{PENDAHULUAN}

Mata kuliah Pengantar Pendidikan merupakan salah satu mata kuliah yang harus diperoleh oleh mahasiswa Prodi Pendidikan Matematika pada semester 1. Tujuan mata kuliah ini memberi bekal kepada mahasiswa sebagai calon guru. Walaupun mahasiswa sudah masuk dalam lingkungan pendidikan, namun mahasiswa belum diberi bekal terkait dengan hakikat manusia, hakikat pendidikan, masalah pendidikan, sistem pendidikan nasional, dan masih banyak lagi materi yang perlu mahasiswa Pendidikan Matematika pahami. Oleh karena itu pencapaian tujuan dari Prodi Pendidikan Matematika bisa terhambat apabila pembelajaran mata kuliah Pengantar Pendidikan berkendala dengan bahan ajar yang masih kurang mendukung hal tersebut.

Sekitar 38\% mahasiswa baru tahun 2012 diharuskan mengikuti matrikulasi. Kurang lebih $50 \%$ dari peserta matrikulasi diwajibkan remidi. Disamping nilai yang kurang mencukupi untuk dinyatakan lulus matrikulasi, kehadiran juga mempengaruhi keputusan tersebut. Hal ini menunjukkan bahwa perlu adanya stimulus agar mahasiswa mempunyai semangat menjadi seorang guru matematika. Jika masih banyak mahasiswa yang berkendala dalam belajar matematika, maka dapat menyebabkan mahasiswa itu sendiri tidak memiliki minat untuk mengajar matematika. Kondisi awal menunjukkan rata-rata minat mahasiswa yaitu 59,74\%, artinya masuk kategori sedang. Hal ini dapat menjadi 
kendala mahasiswa dalam proses perkuliahan berikutnya, karena mereka belum memiliki minat yang tinggi.

Menurut Bruner, sebagaimana dikutip oleh Dahar (1996), suatu teori instruksional hendaknya meliputi: (1) pengalaman-pengalaman optimal bagi siswa untuk mau dan dapat belajar, (2) penstrukturan pengetahuan untuk pemahaman optimal, (3) perincian urutan-urutan penyajian materi pelajaran secara optimal dan (4) bantuk dan pemberian reinforsemen. Jerome Bruner juga menyatakan bahwa belajar matematika akan lebih berhasil jika proses pengajaran diarahkan kepada konsep dan struktur yang terbuat dalam pokok bahasan (Suherman et al., 2003).

Menurut Hudojo (1988) guru perlu mengupayakan hal-hal sebagai berikut: (1) menyediakan pengalaman belajar dengan mengaitkan pengetahuan yang sudah dimiliki siswa sehingga belajar melalui proses pembentukan pengetahuan; (2) mengintegrasikan pembelajaran dengan situasi realistik dan relevan dengan melibatkan pengalaman konkret; (3) mengintegrasikan pembelajaran yang memungkinkan terjadinya interaksi dan kerjasama seseorang dengan orang lain atau lingkungannya; (4) memanfaatkan berbagai media termasuk komunikasi lisan dan tertulis; dan (5) melibatkan siswa secara emosional dan sosial sehingga materi menjadi menarik. Vigostky (dalam Slavin, 2000) menyarankan sikap kooperatif dalam proses belajar sehingga siswa dapat berinteraksi dalam mengerjakan tugastugas yang sulit dan saling memunculkan strategi pemecahan masalah yang efektif di dalam daerah pengembangan masing-masing.

Salah satu alternatif mengatasi masalah di atas yaitu dengan metode pembelajaran Seminar Group melalui Lesson study. Metode pembelajaran Seminar Group memiliki keunggulan yaitu terjadi diskusi kelompok dalam mangkaji suatu materi dan memecahkan masalah yang muncul dalam materi tersebut. Dalam perkuliahan, mahasiswa diminta mempresentasikan makalah hasil dari tugas kelompoknya, setelah itu sesi tanya jawab. Hal ini dapat mempertajam materi dan menambah wawasan lain terkait dengan materi yang sedang dibahas. Winataputra (2001) menyebutkan 4 ciri-ciri metode pembelajaran Seminar Group, yaitu: 1). kelompok terdri dari 5 - 15 peserta, 2). waktu pertemuan lebih dari 45 
menit, 3). membahas makalah yang disajikan, dan 4). penyajian makalah dipilih dari anggota kelompok.

Ada empat macam tugas yang dapat diberikan dosen kepada mahasiswa yang berguna untuk menentukan tugas, yaitu praktikum, studi lapangan, jurnal akademik, dan penulisan makalah (Budiardjo, 2001). Penulisan makalah bagi mahasiswa sudah tidak asing lagi. Namun mahasiswa sering dalam menulis makalah dengan tujuan yang tidak jelas. Akibatnya penulisan makalah sering menjadi terlalu luas dan tidak terarah, bahkan ada yang terlalu sempit karena tidak tahu apa yang hendak ditulis. Ada beberapa langkah dalam memberi tugas menulis makalah, yaitu (1) informasikan tujuan penulisan makalah pada mahasiswa, (2) jelaskan hasil yang diharapkan di akhir makalah, (3) tunjukkan kepada mahasiswa format makalah atau unsur-unsur yang perlu ada di dalam menuliskan makalah, (4) informasikan fasilitas yang disediakan oleh dosen untuk mahasiswa dalam menyelesaikan tugas, (5) memberitahu pedoman penilaian yang akan dipakai untuk menilai makalah tersebut (Budiardjo, 2001).

Menurut Slameto (2010), minat adalah kecenderungan yang tetap untuk memperhatikan dan mengenang beberapa kegiatan. Kegiatan yang diminati seseorang, diperhatikan terus menerus yang disertai dengan rasa senang. Menurut Safari (2005), minat belajar adalah pilihan kesenangan dalam melakukan kegiatan dan dapat membangkitkan gairah seseorang untuk memenuhi kesediaannya dalam belajar. Kemudian definisi operasional dari minat belajar adalah skor siswa yang diperoleh dari tes belajar yang mengukur aspek : (1) kesukacitaan, (2) ketertarikan, (3) perhatian dan (4) keterlibatan.

Pembelajaran akan lebih berkualitas lagi jika melalui implementasi Lesson Study. Masaki (2012) menyatakan, di Indonesia Lesson Study sebagai kegiatan yang terdiri dari tahap plan, do, see. Masaki (2012) menambahkan, Lesson Study adalah suatu kegiatan serta filosofi. Tahap plan, yakni menyusun rencana secara informatif dimana para guru/dosen membahas materi, media atau alat peraga serta cara menjalankan kegiatan pembelajaran. Sedangkan tahap do dan see adalah proses untuk guru/dosen menemukan dan mengungkapkan permasalahn yang terjadi di kegiatan pembelajaran, dan saling belajar dan membelajarkan sesama 
guru/dosen tentang keterampilan mengajar. Berdasarkan pada permasalahan di atas, tujuan dari penelitian ini adalah meningkatkan minat belajar mahasiswa dengan metode pembelajaran Seminar Group melalui implementasi Lesson Study.

\section{METODE PENELITIAN}

Penelitian ini menggunakan metode PTK yang terdiri dari empat siklus. Setiap siklus terdiri dari tahap rencana, tindakan, observasi, dan refleksi (Mulyasa, 2010). Setiap siklus juga meliputi kegiatan yang merupakan implementasi dari Lesson Study: (1) perencanaan (plan), (2) pelaksanaan (do), 3) observasi (do), (4) refleksi (see).

Adapun yang menjadi subjek dalam pengembangan pembelajaran ini adalah mahasiswa matematika FKIP UMP tahun akademik 2012/2013 Semester Ganjil untuk kelas C. Alasan pemilihannya adalah karena menurut pengalaman pengembang bahwa 1) kelas tersebut memiliki minat yang relatif kurang dibandingkan kelas lainnya, 2) belum pernah dilakukan penelitian yang sejenis pada kelas tersebut. Teknik pengumpulan data menggunakan observasi dan angket. Instrumen pengumpulan data menggunakan lembar observasi sesuai format Lesson Study dan angket, digunakan untuk mengumpulkan data tentang aktivitas mahasiswa dan minat belajar mahasiswa. Teknik analisis data menggunakan analisis deskriptif kuantitatif dan kualitatif.

\section{HASIL DAN PEMBAHASAN (ATAU JUDUL LAIN YANG SESUAI)}

Pada siklus I persiapan plan pertama yang dilakukan adalah silabus dan SAP. Hasil penyusunan tersebut disampaikan dan dibahas di dalam tim LS untuk rumpun pendidikan dan tidak ada perubahan yang berarti. Pelaksanaan do pertamakalinya pada pokok materi Landasan dan Asas-asas Pendidikan. Hasil see dari kegiatan ini menunjukkan bahwa praktek pembelajaran secara keseluruhan sudah cukup baik, namun dalam beberapa segi perlu ada perhatian dari dosen model.

Dalam pengamatan mahasiswa masih ada yang berbicara sendiri. Mahasiswa bertanya tetapi pertanyaan mereka belum tajam. Media yang 
digunakan oleh mahasiswa untuk presentasi belum menarik karena berisi kalimat yang dikutip dari makalah yang mereka buat tanpa diringkas. Hal ini mengakibatkan mahasiswa dalam pesentasi secara tekstual,. Posisi duduk belum mendukung mahasiswa untuk berdiskusi dalam kelompoknya masing-masing, sehingga interaksi baik dengan kelompoknya atau dengan yang lain belum terlihat maksimal. Penyusunan tempat duduk dengan huruf $U$ sudah cukup baik, namun belum ada ruang yang cukup untuk observer melaksanakan tugm asnya.

Hasil refleksi dari siklus 1 adalah merekomendasikan kepada dosen model agar memperlihatkan penilaian proses secara terbuka agar mereka dapat memantau kemajuannya sendiri, memperhatikan tempat duduk mahasiswa agar berkelompok untuk memudahkan komunikasi, mengingatkan kepada mahasiswa prinsip-prinsip komunikasi, dan menekankan pada penguasaan konsep. Pada siklus 2, plan diarahkan pada perubahan cara memberikan perhatian pada beberapa aspek yang dipandang masih kurang pada siklus 1 dan tidak dibahas tentang kekurangan perangkat pembelajaran, sehingga skenario pembelajarannya masih menggunakan skenario umum berupa SAP dan silabus yang sudah ada. Plan pada siklus 2 ini lebih diarahkan ke teknik pembelajaran, dalam pembelajaran yang menunjuk untuk bertanya yaitu dosen, posisi tempat duduk dibuat perkelompok dan diperlonggar untuk ruang observer melaksanakan tugasnya.

Dalam siklus ini, do dilakukan pada materi Permasalahan Pendidikan. Dari hasil pemantauan, interaksi mahasiswa sudah bagus dengan posisi tempat duduk yang mengelompok dalam masing-masing kelompok. Hasil see dari kegiatan ini menunjukkan bahwa praktek pembelajaran secara keseluruhan sudah lebih baik, namun dalam beberapa segi perlu ada perbaikan dari dosen model. Pada siklus kedua ini observer menemukan presentator masih membaca tekstual. Mahasiswa mendengarkan dengan semangat terutama pada saat salah satu teman mereka mempresentasikan dengan semangat pula dan memutarkan sebuah video dokumenter. Namun, observer juga menemukan ada seorang mahasiswa yang mengantuk ketika presenter melakukan presentasi. Temuan observer yang lain, mahasiswa yang duduk di bagian tengah masih sering berbicara sendiri, mengipas 
dengan buku dan menulis terus. Pengaturan posisi tempat duduk masih terlalu sempit, hal ini berpengaruh bagi konsentrasi mahasiswa. Saran dari para observer lebih ke pengaturan tempat duduk.

Pada siklus 3 plan lebih difokuskan pada penyusunan denah tempat duduk, SAP dan Silabus masih menggunakan format yang sudah ada. Do yang ketiga dilakukan pada meteri pokok Sistem Pendidikan Nasional. Pada do yang ketiga ini, observer mendapatkan beberapa temuan yaitu mahasiswa banyak yang terlambat, dan masih ada beberapa mahasiswa yang cerita sendiri selama penyaji memaparkan makalahnya. Presentasi terlalu singkat, dimungkinkan karena mahasiswa tidak membaca UU No. 20 tahun 2003 tentang Sistem Pendidikan Nasional. Dalam menjawab pertanyaan, penyaji membutuhkan waktu yang lama. Saran dari observer, dosen model menjadi moderator agar pelaksanaan pembelajaran lebih kondusif.

Pada siklus 4 kegiatan plan diarahkan pada penyempurnaan skenario pembelajaran pada materi Pendidikan dalam pembangunan. Plan pada siklus 4 lebih memperhatikan pada proses diskusi untuk menjamin interaksi belajar yang lebih hidup. Do dilaksanakan tepat waktu dan sudah tidak ada lagi mahasiswa yang terlambat. Dosen bertindak sebagai moderator. Pembelajaran kali ini sudah dilakukan sesuai rencana, namun masih ada temuan observer yaitu ada mahasiswa sedang menyelesaikan tugas matakulaih lain. Usaha dosen memberikan pertanyaan yang membangun, membuat mereka beralih lagi memperhatikan materi yang disampaikan.

Data minat mahasiswa diperoleh dari angket yang disebar setiap siklusnya. Indikator minat mahasiswa yang diamati yaitu kesukacitaan, ketertarikan, perhatian dan keterlibatan. Hasil minat mahasiswa dapat dilihat pada gambar 1 berikut: 


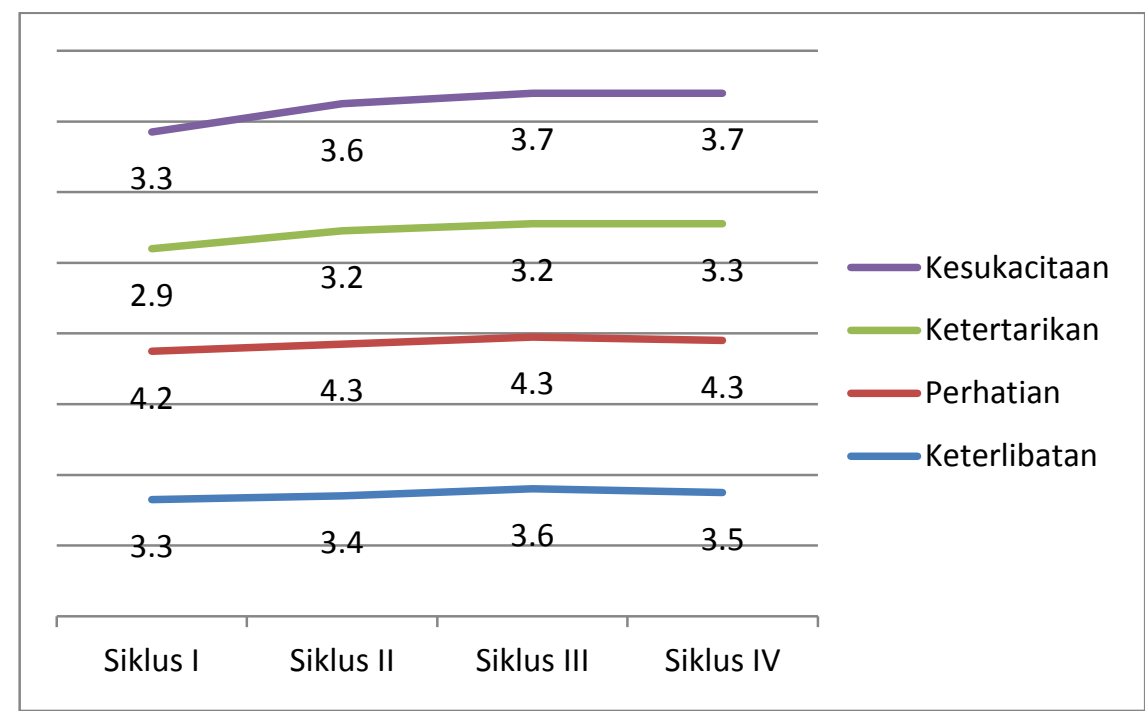

Gambar 1. Grafik Rata-rata minat mahasiswa tiap indikator

Mengenai penilaian minat mahasiswa berpedoman pada kriteria berikut:

$1 \leq$ skor minat $\leq 1,75$ : siswa sangat kurang berminat

$1,75<$ skor minat $\leq 2,5$ : siswa kurang berminat

$2,5<$ skor minat $\leq 3,25$ : siswa berminat

$3,25<$ skor minat $\leq 4$ : siswa sangat berminat

Terkait dengan hasil observasi dengan format Lesson Study menunjukkan bahwa beberapa mahasiswa tidak konsentrasi dalm pembelajaran, bahkan ada yang mengerjakan tugas mata kuliah lain saat proses pembelajaran dan hal ini menyebabkan penurunan pada indikator keterlibatan. Berdasarkan hasil rata-rata minat belajar mahasiswa terlihat hampir semua indicator mengalami peningkatan, walaupun ada sedikit dari beberapa indikator rata-ratanya tetap, ada pula yang terjadi penurunan satu kali pada indikator keterlibatan, hal ini tidak mempengaruhi hasil rata-rata minat mahasiswa tetap meningkat setiap siklunya. Jadi dapat dikatakan setelah melalui implementasi Lesson Study dengan pembelajaran Seminar Group, minat belajar mahasiswa dapat ditingkatkan. Dari keempat siklus rata-rata minat mahasiswa masuk kategori minat belajar tinggi. 


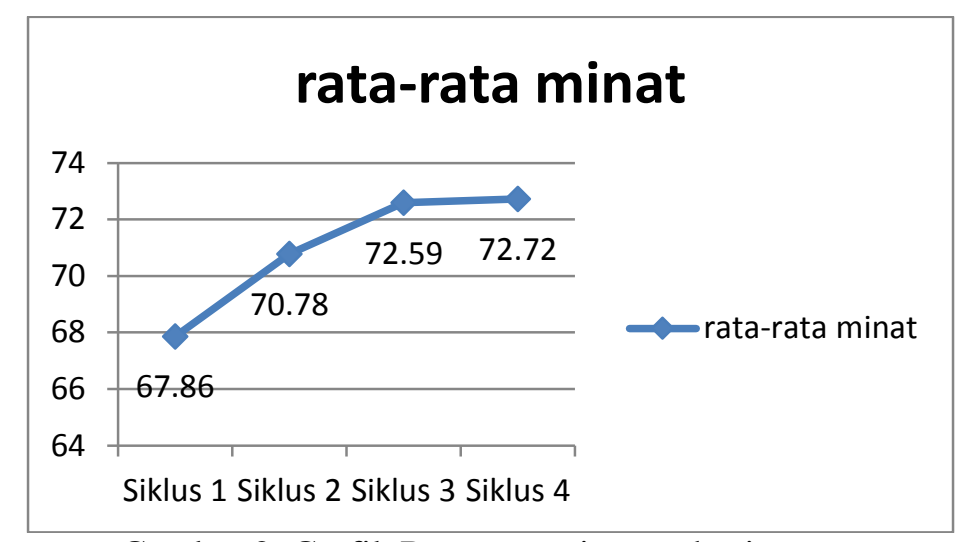

Gambar 2. Grafik Rata-rata minat mahasiswa

Sesuai dengan temuan penelitan diatas maka disarankan bahwa untuk meningkatkan minat belajar mahasiswa dapat digunakan implementasi Lesson Study dengan metode pembelajaran Seminar Group.

\section{KESIMPULAN DAN SARAN}

Simpulan dari penelitian ini yaitu minat belajar mahasiswa meningkat dengan metode pembelajaran Seminar Group melalui implementasi Lesson Study. Sesuai dengan temuan penelitan diatas maka disarankan bahwa untuk meningkatkan minat belajar mahasiswa dapat digunakan implementasi Lesson Study dengan metode pembelajaran Seminar Group. Penggunaan metode pembelajaran yang inovatif seperti halnya Seminar Group menjadi salah cara agar pembelajaran lebih menantang dan menyenangkan.

\section{DAFTAR PUSTAKA}

Budiardjo, Lily. (2001) Metode Pemberian Tugas, Universitas Terbuka, Jakarta.

Dahar, W.R. (1996) Teori-teori Belajar, Erlangga, Jakarta.

Hudojo, H. (1988) Mengajar Belajar Matematika, DIRJEN DIKTI, Jakarta.

Masaki, Sato. (2012) Dialog dan Kolaborasi Sekolah Menengah Pertama, Praktek Learning Community, DEPDIKNAS/DEPAG-JICA.

Mulyasa, H.E. (2010) Praktik Penelitian Tindakan Kelas, Remaja Rosdakarya, Bandung.

Safari. (2005) Penulisan Butir Soal Berdasarkan Penilaian Berbasis Kompetensi, Depdiknas, Jakarta. 
Slameto. (2010) Belajar dan Faktor-faktor yang Mempengaruhinya, Rineka Cipta, Jakarta.

Slavin, E. R. (2000) Cooperative Learning, Theory, Reseach and Practice, Allin \& Bacon Inc, Boston.

Suherman, E, Turmudi, Suryadi, D., Herman, T., Suhendra, Prabawanto, S., Nurjanah, dan Rohayati, A. (2003) Strategi Pembelajaran Matematika Kontemporer, JICA, Bandung.

Winataputra, U. S. (2001) Model-model Pemebelajaran Inovatif, Universitas Terbuka, Jakarta. 